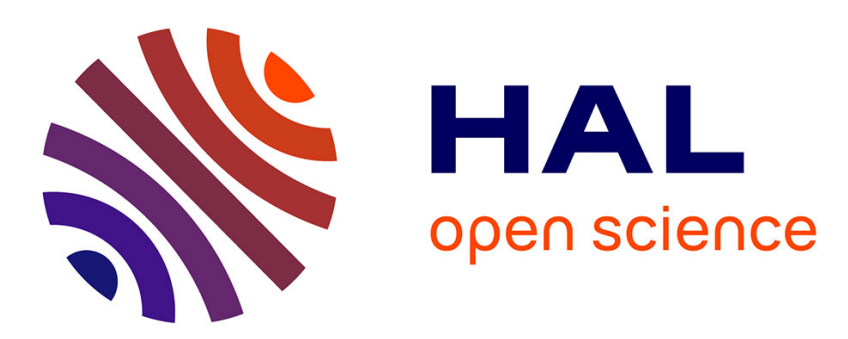

\title{
Genetic polymorphisms associated with blood concentration of lycopene
}

Patrick Borel, Jean-Francois Landrier, Charles Desmarchelier

\section{To cite this version:}

Patrick Borel, Jean-Francois Landrier, Charles Desmarchelier. Genetic polymorphisms associated with blood concentration of lycopene. Tomatoes and lycopene in human nutrition and health, preventing chronic diseases, CRC Press, 2017. hal-01603161

\section{HAL Id: hal-01603161 \\ https://hal.science/hal-01603161}

Submitted on 25 May 2018

HAL is a multi-disciplinary open access archive for the deposit and dissemination of scientific research documents, whether they are published or not. The documents may come from teaching and research institutions in France or abroad, or from public or private research centers.
L'archive ouverte pluridisciplinaire HAL, est destinée au dépôt et à la diffusion de documents scientifiques de niveau recherche, publiés ou non, émanant des établissements d'enseignement et de recherche français ou étrangers, des laboratoires publics ou privés.

\section{다)(1) $(5$}

Distributed under a Creative Commons Attribution - NonCommerciall 4.0 International 


\title{
2 Genetic Polymorphisms Associated with Blood Concentration of Lycopene
}

\author{
Patrick Borel, Jean-François Landrier, \\ and Charles Desmarchelier
}

\section{CONTENTS}

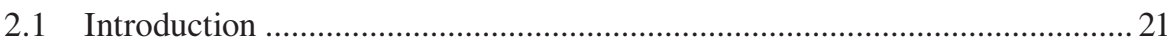

2.2 Lycopene Fate in the Gastrointestinal Lumen during Digestion ....................2 23

2.3 Apical Uptake, Intracellular Metabolism, and Basolateral Secretion

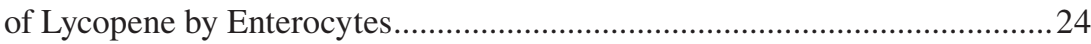

2.4 Regulation of Lycopene Absorption and Cleavage.........................................26

2.5 Postprandial Blood Transport of Newly Absorbed Lycopene from

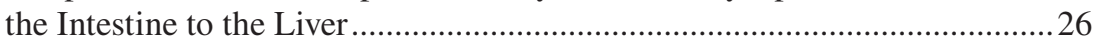

2.6 Liver Metabolism and Blood Transport of Lycopene from the Liver to Extra-Hepatic Tissues............................................................................ 27

2.7 Lycopene Metabolism in Extra-Hepatic Tissues ...........................................28

2.8 Physiological Regulation of Blood Lycopene Concentrations........................28

2.9 Genetic Variations Associated with Blood Lycopene Concentration............. 29

2.9.1 Genetic Variations Associated with Fasting Blood Lycopene Concentration. .29

2.9.2 Genetic Variations Associated with Blood Lycopene Response

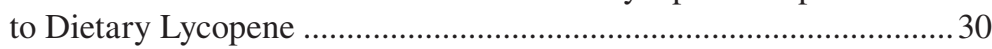

2.10 Other Genetic Variations that Could Be Involved in the Blood

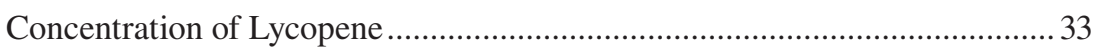

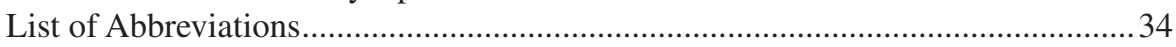

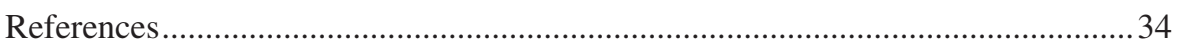

\subsection{INTRODUCTION}

Lycopene is a red pigment found mainly in tomatoes and tomato products. It belongs to the carotenoid family, which contains hundreds of molecules, and more specifically to the carotene class (i.e., non-oxygenated carotenoids). Lycopene is the carotenoid found at the highest concentration in the blood of Americans (mean 23.5-27.4 $\mu \mathrm{g} / \mathrm{dL}$ serum) (Wei, Kim, and Boudreau 2001) and in some geographical regions in Europe, 
for example, Ragusa and Naples in Italia (Al-Delaimy et al. 2004). The interest in this carotenoid has risen in the last decades because it has been suggested to have a protective role against the development of prostate cancer and cardiovascular diseases (Story et al. 2010; Mordente et al. 2011; Bohm 2012; Giovannucci 1999; Viuda-Martos et al. 2014; Biddle et al. 2015; Cheng et al. 2017). The mechanisms that could explain this protective role have yet to be fully elucidated but both in vitro and animal studies have allowed experts to suggest several hypotheses. First of all, since oxidative stress has been implicated in the etiology of these diseases, lycopene has been suggested to exert its protective effect through its antioxidant properties, which have been well characterized in vitro (Kelkel et al. 2011). Nevertheless, lycopene also exhibits biological activities independent of its antioxidant effects: it modulates inflammation (Gouranton et al. 2011; Marcotorchino et al. 2012; Fenni et al. 2017), reduces cholesterol absorption efficiency (Zou and Feng 2015) and there are several studies suggesting that its metabolic products also exert non-antioxidant biological effects (Mein, Lian, and Wang 2008; Gouranton et al. 2011; Aydemir et al. 2013; Gouranton et al. 2012).

Although it is likely that lycopene, together with its metabolites, has various biological effects in our body, its essentiality has not been demonstrated. Thus, it is not considered a nutrient (Hendrich et al. 1994) and there is no recommended dietary allowance for it. Nevertheless, lycopene isomers and lycopene metabolites are present in several organs, tissues, and in our blood. Blood lycopene concentration depends on several factors. The first is obviously the dietary intake of lycopene, as we are unable to synthesize it. The second depends on lycopene absorption efficiency, which is very variable because it depends on several dietary factors (Desmarchelier and Borel 2017) as well as on the ability of each individual to absorb it (Borel et al. 2015b; Bohn et al. 2017). The third is the metabolism of lycopene within the body. Indeed, it is assumed that, after absorption, lycopene is transported from the gut to the liver and then distributed to peripheral tissues. Furthermore, because it is assumed that a significant fraction of lycopene is stored in adipose tissue (Chung et al. 2009), we hypothesize that the higher the fat mass of an individual, the higher their ability to store lycopene in adipose tissue and the lower their blood concentration of lycopene. The fourth group of factors are host-related, e.g., age, gender, disease, and inflammation, which are listed in recent reviews (Desmarchelier and Borel 2017; Bohn et al. 2017). Several mechanisms involved in lycopene absorption and metabolism are governed, directly or indirectly, by proteins. It is therefore assumed that genetic variations that modulate either the activity of the proteins encoded by the genes carrying these genetic variations, or their expression, can affect lycopene absorption and/or metabolism and thus blood and tissue concentrations of lycopene (Borel 2012; Desmarchelier and Borel 2017).

In order to list the genes whose genetic variations could be suspected to affect lycopene absorption and/or lycopene metabolism, it is necessary to describe in detail all the successive metabolic steps that allow lycopene to enter the body and reach the tissues via the blood. Thus, this review starts with a detailed description of the fate of lycopene in the human body, from the food matrix in which it is ingested to extrahepatic tissues via its transit in the liver. This will allow us to identify candidate proteins, and thus candidate genes, that could carry genetic variations able to modulate blood lycopene concentration. This review then lists the genetic variations that have 
been associated with fasting and postprandial blood lycopene concentrations. The review finishes by listing the points to focus on in the forthcoming years to improve our knowledge on the genetic variations that modulate blood lycopene concentration.

\subsection{LYCOPENE FATE IN THE GASTROINTESTINAL LUMEN DURING DIGESTION}

Lycopene is insoluble in water. Thus, although it can be ingested in very different food matrices, e.g., raw tomatoes, tomato paste, or watermelon, it is assumed to transfer, at least in part, from these matrices to lipid droplets of dietary fat emulsions that are present in the gastrointestinal lumen during digestion (Borel 2003; Reboul et al. 2006; Tyssandier et al. 2003; Borel et al. 2001). This transfer, as well as the transfer of lycopene to mixed micelles, is modulated by numerous factors, e.g., food matrix, food processing, or the presence of fibres or lipids. It is beyond the scope of this review to describe the current knowledge on all these factors, but dedicated reviews can be found elsewhere (Borel 2003; Desmarchelier and Borel 2017; Bohn et al. 2015). This transfer can be facilitated by gastric and pancreatic enzymes that

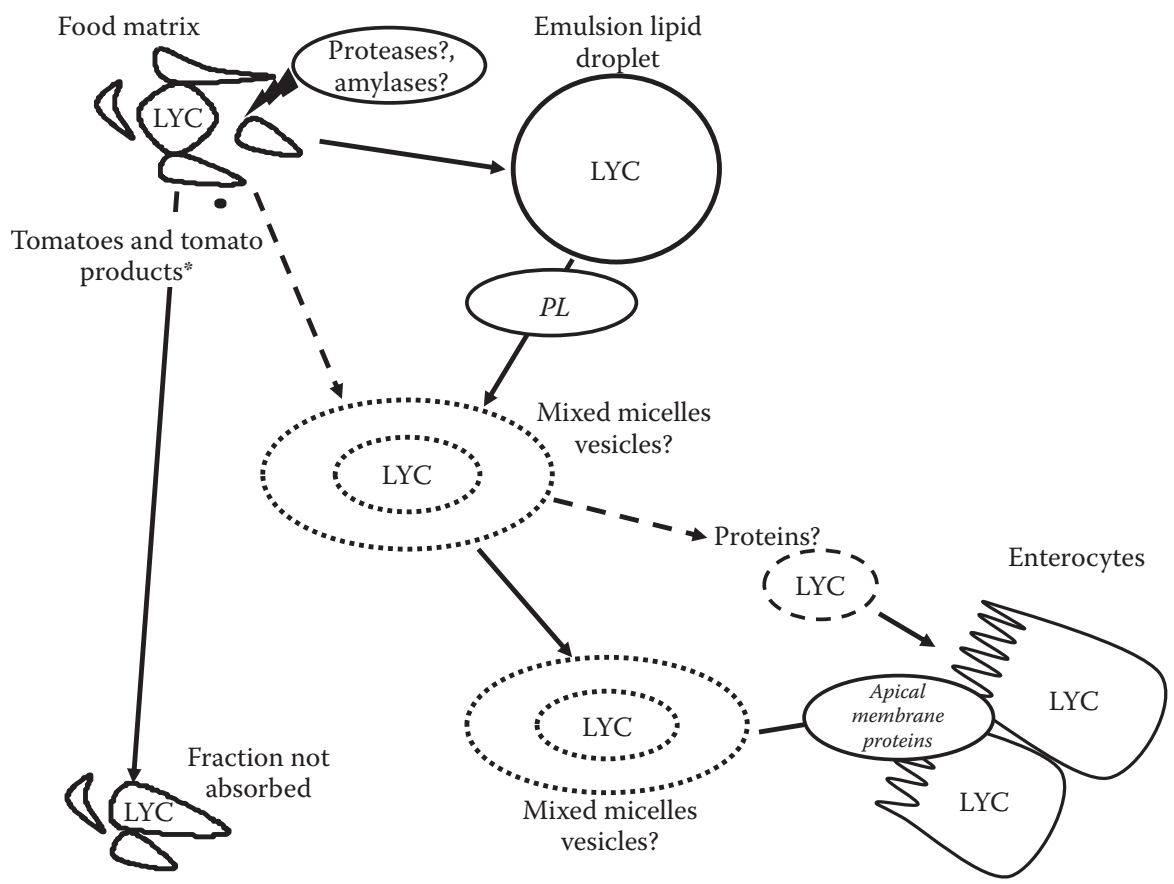

FIGURE 2.1 Proteins involved, or hypothesized to be involved, in lycopene metabolism within the lumen of the upper gastrointestinal tract. LYC: lycopene; PL: pancreatic lipase. Proteins followed by a question mark have been hypothesized to be involved because lycopene is not soluble in water and thus non-micellarized lycopene might be associated with proteins. Question marks and dotted arrows denote that this is suspected to exist but there is as yet no evidence thereof. 
participate in food digestion, i.e. proteases, amylases and lipases (Figure 2.1). The genes that encode these enzymes are thus the first candidates that might affect lycopene absorption and thus blood and tissue lycopene concentrations. Lycopene trans- Please check ferred to lipid droplets, as well as a fraction of lycopene that is still embedded in its larly of the final food matrix, transfer to mixed micelles in the duodenum/jejunum. Again, this trans- "clause beginning fer is assumed to be facilitated by the action of the digestive enzymes (Tyssandier, Lyan, and Borel 2001). Mixed micelles transport lycopene to the apical side of the enterocyte, where it is taken up via both passive diffusion and facilitated transport. Finally, we hypothesize that some lycopene might also associate with protein(s) or peptide(s) that also transport lycopene to the enterocyte.

\subsection{APICAL UPTAKE, INTRACELLULAR METABOLISM, AND BASOLATERAL SECRETION OF LYCOPENE BY ENTEROCYTES}

The mechanism by which micellarized lycopene crosses the apical membrane of the enterocyte is still not accurately known. Nevertheless, studies performed in the last decade have suggested that, contrary to what was previously assumed, lycopene uptake by the enterocyte is not only passive. This is supported by the possible saturation of absorptive mechanisms (Diwadkar-Navsariwala et al. 2003) and by the fact that several proteins, located in the apical membrane of the intestinal cell, have been involved

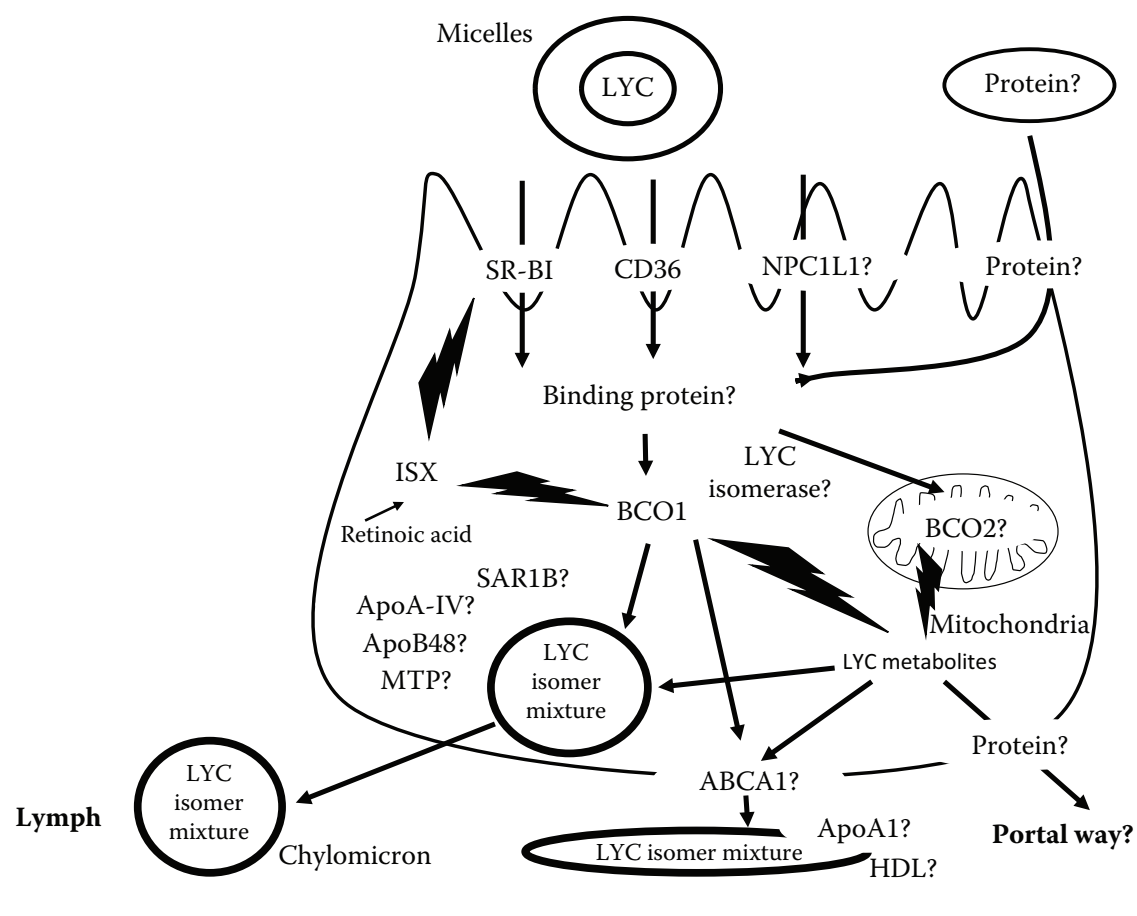

FIGURE 2.2 Proteins involved in lycopene metabolism within the enterocyte. Question marks and dotted arrows denote that this is suspected to exist but there is as yet no evidence thereof. 
in lycopene uptake (Figure 2.2). These proteins are scavenger class B type I (SR-BI) (During, Dawson, and Harrison 2005; Moussa et al. 2008), which are encoded by SCARB1, CD36 molecule (CD36), - although its involvement has been demonstrated only in adipocyte (Moussa et al. 2011) - and NPC1 such as intracellular cholesterol transporter 1 (NPC1L1) - although there is conflicting data on its involvement because one study has suggested it (During, Dawson, and Harrison 2005) while another study has not (Moussa et al. 2008). It is not known whether these proteins have a direct or an indirect effect on lycopene uptake. Indeed, recent results suggest that they might indirectly modulate the apical to intracellular flux of lycopene by modulating the synthesis rate of chylomicrons (Buttet et al. 2014; Briand et al. 2016) in which lycopene is incorporated. Finally, if some lycopene is transported to the apical membrane bound to protein(s), it is not known whether it is absorbed and, if so, what is the mechanism.

After having crossed the apical membrane, lycopene must cross the polarized intestinal cell to be secreted at its basolateral side. Nothing is known about the mechanism involved but it is assumed that it compulsorily implicates proteins because lycopene is insoluble in water. Candidate proteins have been suggested (Reboul and Borel 2011). The first group are the proteins involved in the apical uptake of lycopene that display an intracellular cycle between the apical membrane and the cellular organelles. This is the case of all the above-mentioned proteins, i.e., NPC1L1, CD36, and SR-BI. Indeed, NPC1L1 has been observed in endosomes, perinuclear regions, lysosomes, and mitochondria. CD36 has been detected in the Golgi apparatus. SR-BI has been found in cytoplasmic lipid droplets and in tubulovesicular membranes. We hypothesize that lycopene binds to these proteins, or to apical membrane lipid microdomains containing these proteins, and follows their fate within the cell. The second group are intracellular enterocyte proteins that carry lipids with a broad specificity, e.g., fatty acid binding proteins (liver and intestinal FABPs, i.e., L- and I-FABP), which are both present in the intestine. The fact that a genetic association study has shown that a genetic variant in I-FABP was associated with fasting plasma lycopene concentrations (Borel et al. 2009) supports this hypothesis. The third group is composed of the enzymes responsible for carotenoid metabolism, i.e., beta-carotene oxygenase 1 (BCO1) (Lobo et al. 2012; Amengual et al. 2013) and beta-carotene oxygenase 2 (BCO2) (Hu et al. 2006). BCO1 is cytoplasmic (Lindqvist and Andersson 2002) and it is able to cleave lycopene (Dela Sena et al. 2013; Dela Sena et al. 2016) in the cytosol of mature enterocytes from the jejunum (Duszka et al. 1996). It is thus reasonable to suggest that it is also able to transport lycopene within the cell. Although $\mathrm{BCO} 2$ is able to cleave cis-isomers of lycopene (Hu et al. 2006), we suppose that its mitochondrial localization (Amengual et al. 2011) is not compatible with its involvement as an intracellular transporter of lycopene.

It is not known how all-trans lycopene is isomerized to cis-lycopene isomers in the enterocyte and whether there is a lycopene isomerase involved in this phenomenon, but it has been shown that there is a very efficient isomerization of lycopene in the intestinal cell (Richelle et al. 2010; Ross et al. 2011; Richelle et al. 2012). This explains why, while we eat mostly all-trans lycopene, there are mostly cis-lycopene isomers in our blood and tissues (Stahl et al. 1992).

The secretion mechanism of lycopene at the basolateral side of the intestinal cell likely depends on its cleavage in the enterocyte. Indeed, it is assumed that the parent 
molecules, i.e., the all-trans and cis isomers of lycopene, are incorporated in nascent chylomicrons (Borel et al. 1998), while lycopene metabolites, which are produced by BCO1 or BCO2 (Lindshield et al. 2008; Dela Sena et al. 2013; Dela Sena et al. 2016; Hu et al. 2006; Ford, Elsen, and Erdman 2013), are secreted in the portal blood. However, we suggest that some very hydrophobic lycopene metabolites, i.e., with $\log \mathrm{P}>5$, might be incorporated in chylomicrons as well. The mechanisms responsible for the incorporation of lycopene in chylomicrons are barely known but it is assumed that they involve enzymes/apolipoproteins responsible for the assembly of chylomicrons, e.g., microsomal triglyceride transfer protein (MTP), apoA-IV, secretion associated Ras related GTPase 1B (SAR1B), and apoB48 (Hussain et al. 2005). It has also been suggested that the protein involved in HDL secretion, i.e., ATP-binding cassette, subfamily A, member 1 (ABCA1), might also be involved in lycopene secretion in intestinal HDL (Reboul and Borel 2011).

\subsection{REGULATION OF LYCOPENE ABSORPTION AND CLEAVAGE}

It is as yet unknown whether lycopene absorption and cleavage are regulated. However, the fact that SR-BI is involved in lycopene absorption (During, Dawson, and Harrison 2005; Moussa et al. 2008) and that BCO1 is involved in its cleavage (Dela Sena et al. 2013), suggests that it could be regulated by vitamin A status. Indeed, it has been demonstrated that vitamin A status regulates $\beta$-carotene absorption and cleavage efficiency via a negative feedback loop that involves an intestinal transcription factor called intestine specific homeobox (ISX) (Lobo et al. 2013; Lobo et al. 2010). ISX acts as a repressor of SCARB1 and BCO1 upon retinoic acid activation. When the intracellular concentration of retinoic acid drops, which is assumed to be the case when vitamin A intake is insufficient, ISX exerts less repressor activity towards SCARBI and BCO1 and consequently $\beta$-carotene uptake and conversion efficiency increase. This mechanism might regulate the absorption and the cleavage efficiencies of lycopene as well, although dedicated studies should be performed to verify this hypothesis.

\subsection{POSTPRANDIAL BLOOD TRANSPORT OF NEWLY ABSORBED LYCOPENE FROM THE INTESTINE TO THE LIVER}

As previously stated, newly absorbed lycopene is assumed to be secreted both as a mixture of all-trans and cis-isomers of the parent molecules in chylomicrons, and as lycopene metabolites in the portal blood. Concerning the second pathway, there is no information, but it can be suggested that the water-soluble metabolites of lycopene are solubilized in the portal blood and/or are incorporated in intestinal HDL and carried to the liver. Concerning the apo-B-dependent pathway, it is assumed that the all-trans and the cis isomers of lycopene are carried by chylomicrons to the liver, where they are taken up. Indeed, lycopene is apparently not significantly exchanged between lipoproteins (Romanchik, Morel, and Harrison 1995; Tyssandier et al. 2002) and thus it is assumed that it stays in the chylomicrons during their intravascular metabolism. However, these studies were performed with the alltrans isomer and it is possible that the cis-isomers are able to significantly transfer 
between lipoproteins or to transfer from lipoproteins to tissues during intravascular chylomicron metabolism (Zaripheh and Erdman 2005). Whatever the proportion of lycopene that is transferred to other lipoproteins or to tissues during chylomicron metabolism, it is assumed that the remaining fraction is taken up by the liver via the chylomicron-remnant receptors, i.e., the LDL-receptor (LDLR), the LDL-receptor related protein 1 (LRP1), and the heparan sulfate proteoglycans (HSPGs) (DallingaThie et al. 2010).

\subsection{LIVER METABOLISM AND BLOOD TRANSPORT OF LYCOPENE FROM THE LIVER TO EXTRA-HEPATIC TISSUES}

Liver is the primary depot organ for lycopene (Mathews-Roth et al. 1990; Schmitz et al. 1991; Ferreira et al. 2000; Zaripheh et al. 2003; Korytko et al. 2003). Following chylomicron-remnant uptake by the liver, it is assumed that lycopene is released in hepatocytes (Figure 2.3). It is then assumed that it is transferred, by an unknown mechanism but that likely involves protein(s) (since lycopene is insoluble in the water environment of the cell), to the fat-storing cells (also called lipocytes), hepatic stellate cells, or Ito cells. Indeed, these cells, which are well known to store vitamin A (Borel and Desmarchelier 2017), are apparently also able to store lycopene (Teodoro

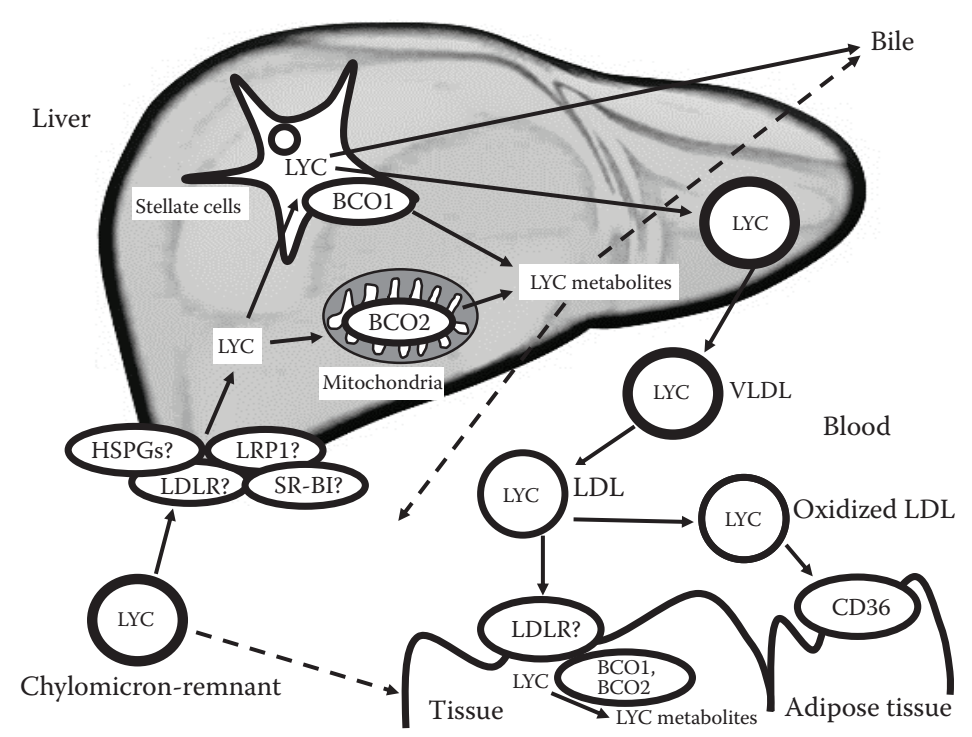

Abbreviations removed, as

these are listed at the end of the chapter

and don't need

to be repeated.

Please confirm

this is OK.
FIGURE 2.3 Proteins involved in the liver metabolism of lycopene. This figure shows current knowledge on the proteins involved in the liver metabolism of lycopene and in its distribution to peripheral tissues. Lycopene reaches the liver incorporated in chylomicron remnants following lycopene absorption. Lycopene is then mostly stored in hepatic stellate cells. The liver is assumed to be a hub of lycopene metabolism. Indeed, it is the main organ that stores lycopene and distributes it to the peripheral tissues. Question marks and dotted arrows denote that this is suspected to exist but there is as yet no evidence thereof. 
et al. 2009). Again, it is not known how lycopene stored in these cells is mobilized, and which proteins are involved. Concerning its liver metabolism, it likely depends on lycopene isomerization. Indeed, the all-trans isomer is only cleaved by BCO1 (Lindshield et al. 2008; Dela Sena et al. 2013; Dela Sena et al. 2016), which is highly expressed in hepatic stellate cells (Shmarakov et al. 2010), while the 5-cis and 13-cis isomers are only cleaved by BCO2 (Hu et al. 2006; Ford, Elsen, and Erdman 2013). It is assumed that the fraction of lycopene that is not metabolized or stored in the liver is either secreted in the bile (Leo et al. 1995) or in the blood, mainly in VLDL. It is not known whether the liver also secretes lycopene metabolites in the blood. Because it is assumed that LDL, which originates from intravascular metabolism of VLDL, are responsible for the distribution of lycopene to peripheral tissues, it is hypothesized that only tissues that express the LDL-receptor can take up lycopene. However, it has been shown that CD36, which is able to bind oxidized LDL, is involved in adipose tissue uptake of lycopene (Moussa et al. 2008), and it cannot be excluded that a fraction of lycopene can reach some tissues during chylomicron metabolism (Zaripheh and Erdman 2005).

\subsection{LYCOPENE METABOLISM IN EXTRA-HEPATIC TISSUES}

The metabolism of lycopene in extra-hepatic tissues is barely known. It is out of the scope of this review to exhaustively list what is known in each tissue but it is necessary to talk about adipose tissue. Indeed, since it is assumed that a significant fraction of lycopene is stored in this tissue (Chung et al. 2009), we hypothesize that the ability of adipose tissue to store lycopene, or after storage to resecrete it, could have a significant impact on blood lycopene concentration.

\subsection{PHYSIOLOGICAL REGULATION OF BLOOD LYCOPENE CONCENTRATIONS}

The blood concentration of lycopene can significantly vary during the period that follows a meal rich in lycopene when compared to the fasting state. For example, it increased from about 460 to about $560 \mathrm{nmol} / \mathrm{l}$ after intake, by healthy adults, of a meal that provided $19 \mathrm{mg}$ of lycopene in tomato paste (Borel et al. 2016). Thus, when talking about blood lycopene concentration, it is important to specify when its concentration is measured, i.e., in the fasting period or during the postprandial period.

It is assumed that there is no direct regulation of blood lycopene concentration. In the fasting state about $75 \%$ of lycopene is transported in LDL (Romanchik, Morel, and Harrison 1995; Goulinet and Chapman 1997) but it is also found in VLDL and HDL. During the postprandial period, it is transported both in these lipoproteins and in chylomicrons (if a meal containing lycopene was ingested). Thus, we assume that blood concentration of lycopene mainly depends: 1) on the state at which the blood is collected, i.e., at fast or in the postprandial period, and when in the postprandial time; 2) on the amount of lycopene that is usually ingested by the subject, which is a key factor governing its LDL concentration; 3) on the amount of lycopene that was ingested in the meal that preceded blood sampling; 4) on the subject metabolism of 
lipoproteins in which lycopene is incorporated; and 5) on the ability of the subject to store/resecrete lycopene in/from their adipose tissue, which in turn depends on their body fat mass and on the metabolism of lycopene in their adipose tissue. Thus, blood lycopene concentration is likely modulated by several proteins, the main ones being those that regulate LDL (Garcia-Rios et al. 2012) and chylomicron metabolism (Dallinga-Thie et al. 2010; Perez-Martinez et al. 2010; Desmarchelier et al. 2014).

\subsection{GENETIC VARIATIONS ASSOCIATED WITH BLOOD LYCOPENE CONCENTRATION}

Clinical trials have systematically reported a huge interindividual variability in blood and tissue lycopene response to lycopene intake (Stahl and Sies 1992; Bowen et al. 1993; Johnson et al. 1997; O'Neill and Thurnham 1998; Diwadkar-Navsariwala et al. 2003; Wang, Edwards, and Clevidence 2013; Forman et al. 2009; Gustin et al. 2004; Borel et al. 2015b). For example, the coefficient of variation of the postprandial chylomicron lycopene response measured in 33 healthy subjects after the intake of a test meal that provided $9.7 \mathrm{mg}$ lycopene in $100 \mathrm{~g}$ of tomato puree was $70 \%$ (Borel et al. 2015b). Genetic variations between individuals have been suggested to explain, at least in part, this phenomenon (Borel 2012; Moran, Erdman, and Clinton 2013; Desmarchelier and Borel 2017; Bohn et al. 2017). It has even been suggested that ethnically related genetic variants can influence blood carotenoid concentration (Arab et al. 2011). The use of genome-wide association studies (GWAS) to identify genetic variations associated with diseases (van der Sijde, $\mathrm{Ng}$, and Fu 2014) and various phenotypes is relatively recent. These studies usually require the recruitment of thousands of subjects and are thus very expensive. This explains why there are only three GWAS dedicated to identifying genetic variations associated with blood lycopene concentration (Ferrucci et al. 2009; Zubair et al. 2015; D'Adamo et al. 2016). This also explains why there is no GWAS dedicated to identifying genetic variations associated with lycopene bioavailability. Indeed, the measurement of this phenotype requires a postprandial study, which cannot be performed easily across thousands of volunteers. In fact, there is only one candidate gene association study (CGAS) dedicated to identifying genetic variations associated with this phenotype (Borel et al. 2015b).

\subsubsection{Genetic Variations Associated with Fasting Blood Lycopene Concentration}

The three GWAS dedicated to identifying genetic variations associated with fasting blood lycopene concentration (Ferrucci et al. 2009; Zubair et al. 2015; D'Adamo et al. 2016) have identified single nucleotide polymorphisms (SNPs) in or near five

Please check if changed to is correct. genes (Table 2.1). In alphabetical order: BCO1 (Ferrucci et al. 2009), dehydrogenase/ reductase 2 (DHRS2) (Zubair et al. 2015), SCARB1 (Zubair et al. 2015; D'Adamo et al. 2016), SET domain containing lysine methyltransferase 7 (SETD7) (D'Adamo et al. 2016) and slit guidance ligand 3 (SLIT3) (Zubair et al. 2015). It should be reminded that GWAS do not make any assumption on the genes that can affect the studied 
disease/phenotype and thus allow us to identify associations that were not expected to be involved in the studied disease/phenotype, in this case fasting blood lycopene concentration. This is the case for the associations found with SLIT3, STED7 and DHRS2. In fact, the associations with SLIT3 and SETD7 were not explained by the authors. SLIT3 serves as a molecular guidance cue in cellular migration, and SETD7 is one of the histone methyltransferases (HMTs) enzymes. Current knowledge on lycopene metabolism does not allow us to suggest a simple explanation of these associations. Concerning DHRS2, which encodes for an oxidoreductase, the authors only hypothesized that "it could be involved in lycopene metabolism." Thus, further studies should confirm these associations and try to explain the role of these genes on blood lycopene concentration. The associations found with SCARB1 and BCO1 are easier to explain. SCARB1 encodes for SR-BI, which is involved in lycopene absorption and tissue uptake (During, Dawson, and Harrison 2005; Moussa et al. 2008) and BCO1 encodes for beta-carotene oxygenase 1, which is able to cleave lycopene (Dela Sena et al. 2013). The GWAS have thus confirmed the key role of these proteins/ genes in lycopene metabolism.

Only two CGAS were dedicated to study associations between genetic variations in genes assumed to be involved in lycopene metabolism and fasting blood lycopene concentration (Borel et al. 2009; Borel et al. 2007) (Table 2.1). These studies focused on genes involved in lipid metabolism because lycopene is transported/stored in lipid structures in our body, e.g., lipoproteins or membranes, and it is thus assumed that its metabolism is closely related to that of lipids. These CGAS have found that SNPs in I-FABP, apoB and apoA-IV were associated with fasting blood lycopene concentration. These associations were not found in the GWAS. Thus, they likely play a minor role in this phenotype and they should be replicated in other studies. However, it should be reminded that GWAS usually lead to false negative associations, i.e., to the rejection of genetic variants that are actually associated with the studied disease/ phenotype, because of the statistical stringency used in this approach.

\subsubsection{Genetic Variations Associated with Blood LyCopene Response to Dietary Lycopene}

Although the identification of genetic variations associated with fasting blood lycopene concentration is of interest to better understand lycopene metabolism, the application of the results to clinical practice or dietary recommendations is otherwise not straightforward. Indeed, the highest risk factor for developing low blood lycopene concentration is usually low lycopene intake. Nevertheless, since lycopene displays a huge interindividual variability in its bioavailability, which is partly due to genetic variants, the objective to increase blood lycopene concentration should rely on identifying tailored nutritional strategies, i.e., based on the assessment of the lycopene responder phenotype of a population/individual. For example, an individual, or a group of individuals, exhibiting low blood lycopene concentrations with high capacity to absorb lycopene could be advised to increase their intake of lycopene-rich foods to increase their lycopene status. Conversely, this dietary recommendation will likely fail in subjects who are low responders to dietary lycopene and who will need supplements very rich in lycopene to improve their lycopene status. 
To our knowledge, there are only two studies dedicated to identifying genetic variations associated with blood lycopene response to dietary lycopene (Table 2.1). The first one examined the plasma lycopene response to consumption of lycopenerich beverages for three weeks (Wang, Edwards, and Clevidence 2013). In that study, individual responsiveness was associated with genetic variants in $\mathrm{BCO}$. The second study was dedicated to identifying a combination of genetic variants associated with lycopene bioavailability, which was evaluated by the postprandial chylomicron lycopene response to a test meal that provided tomato puree as a source of lycopene (Borel et al. 2015b). This study showed that lycopene bioavailability was associated with a combination of 28 SNPs in or near 16 candidate genes (Table 2.1). Seven of these genes-ABCA1, lipoprotein lipase (LPL), insulin induced gene 2 (INSIG2), solute carrier, family 27, member 6 (SLC27A6), lipase C, hepatic type (LIPC), CD36, and APOB - had been associated with the postprandial chylomicron triacylglycerol response in the same group of subjects (Desmarchelier et al. 2014). This was not surprising as most newly absorbed lycopene is carried from the intestine to peripheral organs via chylomicrons, which are mainly composed of triacylglycerols. Nevertheless, four of these genes, i.e., ELVOL2, MTTP, ABCB1 and SOD2, were specifically and significantly associated with lycopene bioavailability. Possible explanations why these genes were associated with the lycopene bioavailability are discussed in the original paper (Borel et al. 2015a). In summary, ELOVL2 is known to catalyze the elongation of EPA (eicosapentaenoic acid) to DPA (docosapentaenoic acid) and DPA to DHA (docosahexaenoic acid). Although lycopene is not considered to be a substrate for this enzyme, the fact that SNPs in this gene were also associated with both lutein (Borel et al. 2014) and $\beta$-carotene bioavailability (Borel et al. 2015a) strongly suggest that ELOVL2 is involved, directly or indirectly, in carotenoid, and thus lycopene, metabolism. MTTP encodes for the microsomal triglyceride transfer protein, which is involved in the packaging of triacylglycerols within the chylomicrons. Its association with lycopene bioavailability is therefore not surprising, as lycopene is incorporated into chylomicrons in the enterocyte. ABCB1 encodes for the P-glycoprotein, an ATP-dependent drug efflux pump for xenobiotics with broad substrate specificity. Its association suggests that this protein may participate in lycopene net absorption, possibly by effluxing a fraction of uptaken lycopene back to the intestinal lumen. SOD2 is responsible for converting superoxide by-products to hydrogen peroxide and diatomic oxygen. It was hypothesized that, when this enzyme is not efficient, superoxide by-products are quenched by lycopene, leading to its degradation. Surprisingly, SNPs in genes assumed to be involved in lycopene absorption and metabolism were not associated with lycopene bioavailability. These SNPs were in SCARB1 and CD36, which encode for proteins involved in the cellular uptake of lycopene (During, Dawson, and Harrison 2005; Moussa et al. 2008; Moussa et al. 2011), and $\mathrm{BCO} 1$ and $\mathrm{BCO} 2$, which are able to cleave various isomers of lycopene. Several hypotheses have been suggested in the original paper to explain this lack of association (Borel et al. 2015b). It was first hypothesized that SNPs genotyped in these genes do not result in a functionally different phenotype with regards to lycopene bioavailability. It was also hypothesized that the association of SNPs in these genes was weaker than that of the SNPs in the selected partial least square model. It was finally hypothesized that some SNPs in these genes were not entered in the 


\section{TABLE 2.1 \\ Summary of SNPs Associated with Fasting Blood Lycopene Concentration or Blood Lycopene Response to Dietary Lycopene}

\begin{tabular}{|c|c|c|c|}
\hline SNP & $\begin{array}{c}\text { Global } \\
\text { MAF }\end{array}$ & $\begin{array}{c}\text { Nearest } \\
\text { Gene }\end{array}$ & Trait \\
\hline rs6564851 & 0.476 & $\mathrm{BCO} 1$ & FB-LYC \\
\hline rs74036811 & 0.020 & DHRS2 & FB-LYC \\
\hline rs7680948 & 0.341 & SETD7 & FB-LYC \\
\hline rs1672879 & 0.269 & SCARB1 & FB-LYC \\
\hline rs11057841 & 0.179 & SCARB1 & FB-LYC \\
\hline rs78219687 & 0.017 & SLIT3 & FB-LYC \\
\hline Apo A-IV-Ser347 & 0.025 & APOAIV & FB-LYC \\
\hline Apo B -516 & 0.085 & APOB & FB-LYC \\
\hline I-FABP-Thr & 0.089 & IFABP & FB-LYC \\
\hline rs12934922 & 0.357 & BCO1 & FB-LYC-R \\
\hline rs7501331 & 0.213 & $\mathrm{BCO} 1$ & FB-LYC-R \\
\hline rs $1331924^{\mathrm{e}}$ & 0.245 & ABCA1 & LYC-B $^{\mathrm{d}}$ \\
\hline rs $2791952^{\mathrm{e}}$ & 0.140 & ABCA1 & LYC-B \\
\hline rs $3887137^{\mathrm{e}}$ & 0.123 & ABCA1 & LYC-B \\
\hline rs4149299e & 0.082 & ABCA1 & LYC-B \\
\hline $\mathrm{rs} 4149316^{\mathrm{e}}$ & 0.122 & ABCA1 & LYC-B \\
\hline rs 10248420 & 0.347 & ABCB1 & LYC-B \\
\hline rs10280101 & 0.145 & ABCB1 & LYC-B \\
\hline rs1871744 & 0.499 & ABCG2 & LYC-B \\
\hline rs $1042031^{\mathrm{e}}$ & 0.153 & APOB & LYC-B \\
\hline rs4112274 & 0.224 & CD36 & LYC-B \\
\hline rs3798709 & 0.252 & ELOVL2 & LYC-B \\
\hline rs911196 & 0.252 & ELOVL2 & LYC-B \\
\hline rs9468304 & 0.302 & ELOVL2 & LYC-B \\
\hline rs $17006621^{\mathrm{e}}$ & 0.172 & INSIG2 & LYC-B \\
\hline rs2056983 & 0.117 & ISX & LYC-B \\
\hline rs12914035 & 0.096 & LIPC & LYC-B \\
\hline rs $8035357^{e}$ & 0.150 & LIPC & LYC-B \\
\hline rs $17482753^{e}$ & 0.088 & LPL & LYC-B \\
\hline rs 7005359e & 0.298 & LPL & LYC-B \\
\hline rs7841189e & 0.148 & LPL & LYC-B \\
\hline rs 1032355 & 0.251 & MTTP & LYC-B \\
\hline rs 17029173 & 0.135 & MTTP & LYC-B \\
\hline rs 745075 & 0.095 & MTTP & LYC-B \\
\hline rs 17725246 & 0.254 & NPC1L1 & LYC-B \\
\hline rs935933 & 0.139 & PKD1L2 & LYC-B \\
\hline rs11197742 & 0.087 & PNLIP & LYC-B \\
\hline
\end{tabular}

Study

Type

(Ferrucci et al. 2009)

(Zubair et al. 2015)

(D'Adamo et al. 2016)

GWAS $^{\text {a }}$ Please check if

GWAS $^{\text {b }} \begin{aligned} & \text { were properly } \\ & \text { captured. }\end{aligned}$

(Zubair et al. 2015)

(D’Adamo et al. 2016)

(Zubair et al. 2015)

GWAS

(Borel et al. 2007)

GWAS $^{\mathrm{a}}$

(Borel et al. 2007)

GWAS $^{\mathrm{b}}$

(Borel et al. 2009)

CGAS

CGAS

(Wang, Edwards, and

Clevidence 2013)

(Wang, Edwards, and

CGAS

CGAS

Clevidence 2013)

(Borel et al. 2015b) CGAS

(Borel et al. 2015b) CGAS

(Borel et al. 2015b) CGAS

(Borel et al. 2015b) CGAS

(Borel et al. 2015b) CGAS

(Borel et al. 2015b) CGAS

(Borel et al. 2015b) CGAS

(Borel et al. 2015b) CGAS

(Borel et al. 2015b) CGAS

(Borel et al. 2015b) CGAS

(Borel et al. 2015b) CGAS

(Borel et al. 2015b) CGAS

(Borel et al. 2015b) CGAS

(Borel et al. 2015b) CGAS

(Borel et al. 2015b) CGAS

(Borel et al. 2015b) CGAS

(Borel et al. 2015b) CGAS

(Borel et al. 2015b) CGAS

(Borel et al. 2015b) CGAS

(Borel et al. 2015b) CGAS

(Borel et al. 2015b) CGAS

(Borel et al. 2015b) CGAS

(Borel et al. 2015b) CGAS

(Borel et al. 2015b) CGAS

(Borel et al. 2015b) CGAS

(Borel et al. 2015b) CGAS

(Continued) 
TABLE 2.1 (CONTINUED)

Summary of SNPs Associated with Fasting Blood Lycopene Concentration or Blood Lycopene Response to Dietary Lycopene

$\begin{array}{llcccc}\text { SNP } & \begin{array}{c}\text { Global } \\ \text { MAF }\end{array} & \begin{array}{c}\text { Nearest } \\ \text { Gene }\end{array} & \text { Trait } & \text { Reference } & \begin{array}{c}\text { Study } \\ \text { Type }\end{array} \\ \text { rs10053477e } & 0.209 & \text { SLC27A6 } & \text { LYC-B } & \text { (Borel et al. 2015b) } & \text { CGAS } \\ \text { rs9365046 } & 0.169 & \text { SOD2 } & \text { LYC-B } & \text { (Borel et al. 2015b) } & \text { CGAS }\end{array}$

Note: The official gene symbols are those found in PubMed (available online: https://www.ncbi.nlm .nih.gov/gene/) and approved by the Hugo Gene Nomenclature Committee (available online: http:// www.genenames.org/).

Abbreviations: CGAS: candidate gene association study; GWAS: genome-wide association study; MAF: minor allele frequency (https://www.ncbi.nlm.nih.gov/projects/SNP/); FB-LYC: fasting blood lycopene concentration; FB-LYC-R: fasting blood lycopene response to dietary lycopene; LYC-B: lycopene bioavailability.

a Nominal association.

b Associations detected in African-Americans but not in Caucasian Americans of European descent.

c In this study, lycopene bioavailability was estimated by measuring the postprandial chylomicron lycopene response to a lycopene-rich test meal ( 0 to $8 \mathrm{~h}$, area under the curve).

partial least square regression analysis because either they were not expressed on the BeadChips, or they were excluded from the analysis (for not following the HardyWeinberg equilibrium or because their genetic call rate was $<95 \%)$. Nevertheless, only further studies will allow us to answer whether these genes are not key genes with regard to lycopene bioavailability, at least when it is evaluated by the method used in this paper, or whether this lack of associations is due to another hypothesis.

\subsection{OTHER GENETIC VARIATIONS THAT COULD BE INVOLVED IN THE BLOOD CONCENTRATION OF LYCOPENE}

The low number of available studies presented in the previous paragraphs highlights the tremendous work that remains to be done to identify all the genetic variations associated with blood lycopene concentration (Table 2.1). Furthermore, there is still no study dedicated to identifying genetic variations that could modulate lycopene concentration in different tissues. It should also be remembered that, although SNPs represent $\approx 90 \%$ of genetic polymorphisms, other genetic variations occur in DNA, e.g., copy number variants, insertion/deletion of some base pairs, and epigenetic modifications. A genetic score that would aim to predict lycopene concentration in blood and in different tissues should therefore consider all the genetic variations that can have a significant impact on these concentrations. Finally, association studies must be performed in different populations to be sure that the associations are not specific to some ethnic groups. 
In summary, there is now enough evidence to state that blood, and likely tissue, lycopene concentration, and lycopene bioavailability, are partly modulated by genetic variations in several genes. However, a lot of work remains to be done to propose combinations of genetic variations (SNPs, but also other kinds of genetic variations) that will allow us to confidently predict the concentration of lycopene in the blood or in the tissue of an individual by knowing his genotype at these variations. Yet, the potential usefulness of this area of research is exciting regarding personalized nutrition. Finally, it is important to remember that genetics only represents one of the factors that affect lycopene concentration in blood and tissues, albeit stable over the lifespan, since other factors, such as lycopene dietary intake, and factors that affect lycopene bioavailability (e.g., cooking practice), also affect this status. Thus, a prediction of lycopene concentration in blood and in various tissues should also consider these variables.

\section{LIST OF ABBREVIATIONS}

$\begin{array}{ll}\text { ABCA1 } & \text { (ATP-binding cassette, subfamily A, member 1) } \\ \text { ABCB1 } & \text { (ATP-binding cassette, subfamily B (MDR/TAP), member 1) } \\ \text { BCO1 } & \text { ( } \beta \text {-carotene oxygenase 1) } \\ \text { BCO2 } & \text { ( } \beta \text {-carotene oxygenase }) \\ \text { CD36 } & \text { (CD36 molecule) } \\ \text { DHRS2 } & \text { (dehydrogenase/reductase 2) } \\ \text { ELOVL2 } & \text { (ELOVL fatty acid elongase }) \\ \text { HSPGs } & \text { (heparan sulfate proteoglycans) } \\ \text { INSIG2 } & \text { (insulin-induced gene 2) } \\ \text { ISX } & \text { (intestine specific homeobox) } \\ \text { LDLR } & \text { (LDL-receptor) } \\ \text { L-FABP } & \text { (liver-fatty acid binding protein) } \\ \text { LIPC } & \text { (lipase C, hepatic type) } \\ \text { LPL } & \text { (lipoprotein lipase) } \\ \text { LRP1 } & \text { (LDL-receptor related protein 1) } \\ \text { MTTP } & \text { gene/MTP protein (microsomal triglyceride transfer protein) } \\ \text { SAR1B } & \text { (secretion associated Ras related GTPase 1B) } \\ \text { SCARB1 } & \text { gene/SR-BI protein (scavenger receptor, class B, member 1) } \\ \text { SETD7 } & \text { (SET domain containing lysine methyltransferase 7) } \\ \text { SLC27A6 } & \text { (solute carrier, family 27, member 6) } \\ \text { SLIT3 } & \text { (slit guidance ligand 3) } \\ \text { SNPs } & \text { (single nucleotide polymorphisms) } \\ \text { SOD2 } & \text { (superoxide dismutase 2, mitochondrial) } \\ & \end{array}$

Please provide all author "et al." where "et al." is listed in References. Please also abbreviate each journal.

\section{REFERENCES}

Al-Delaimy, W. K., A. L. van Kappel, P. Ferrari et al. 2004. "Plasma levels of six carotenoids in nine European countries: Report from the European Prospective Investigation into Cancer and Nutrition (EPIC)." Public Health Nutr 7 (6):713-22.

Amengual, J., G. P. Lobo, M. Golczak et al. 2011. "A mitochondrial enzyme degrades carotenoids and protects against oxidative stress." Faseb J 25 (3):948-59. 
Amengual, J., M. A. Widjaja-Adhi, S. Rodriguez-Santiago et al. 2013. "Two carotenoid oxygenases contribute to mammalian provitamin A metabolism." J Biol Chem 288 (47):34081-96.

Arab, L., M. C. Cambou, N. Craft, K. Wesseling-Perry, P. Jardack, and A. Ang. 2011. "Racial differences in correlations between reported dietary intakes of carotenoids and their concentration biomarkers." Am J Clin Nutr 93 (5):1102-8.

Aydemir, G., Y. Kasiri, E. Birta et al. 2013. "Lycopene-derived bioactive retinoic acid receptors/ retinoid-X receptors-activating metabolites may be relevant for lycopene's anti-cancer potential." Mol Nutr Food Res 57 (5):739-47.

Biddle, M. J., T. A. Lennie, G. V. Bricker, R. E. Kopec, S. J. Schwartz, and D. K. Moser. 2015. "Lycopene dietary intervention: A pilot study in patients with heart failure." J Cardiovasc Nurs 30 (3):205-12.

Bohm, V. 2012. "Lycopene and heart health." Mol Nutr Food Res 56 (2):296-303.

Bohn, T., C. Desmarchelier, L. O. Dragsted et al. 2017. "Host-related factors explaining interindividual variability of carotenoid bioavailability and tissue concentrations in humans." Mol Nutr Food Res: In press.

Bohn, T., G. J. McDougall, A. Alegria et al. 2015. "Mind the gap-deficits in our knowledge of aspects impacting the bioavailability of phytochemicals and their metabolites-A position paper focusing on carotenoids and polyphenols." Mol Nutr Food Res 59 (7):1307-23.

Borel, P. 2003. "Factors affecting intestinal absorption of highly lipophilic food microconstituents (fat-soluble vitamins, carotenoids and phytosterols)." Clin Chem Lab Med 41 (8):979-94.

Borel, P. 2012. "Genetic variations involved in interindividual variability in carotenoid status." Mol Nutr Food res 56:228-40.

Borel, P. and C. Desmarchelier. 2017. "Genetic variations associated with vitamin A status and vitamin A bioavailability." Nutrients 9 (246): In press.

Borel, P., C. Desmarchelier, U. Dumont et al. 2016. "Dietary calcium impairs tomato lycopene bioavailability in healthy humans." Br J Nutr 116 (12):2091-6.

Borel, P., C. Desmarchelier, M. Nowicki, and R. Bott. 2015a. "A Combination of SingleNucleotide Polymorphisms Is Associated with Interindividual Variability in Dietary beta-Carotene Bioavailability in Healthy Men." J Nutr 145:1740-7.

Borel, P., C. Desmarchelier, M. Nowicki, and R. Bott. 2015b. "Lycopene bioavailability is associated with a combination of genetic variants." Free Radic Biol Med 83:238-44.

Borel, P., C. Desmarchelier, M. Nowicki, R. Bott, S. Morange, and N. Lesavre. 2014. "Interindividual variability of lutein bioavailability in healthy men: Characterization, genetic variants involved, and relation with fasting plasma lutein concentration." Am J Clin Nutr 100 (1):168-75.

Borel, P., P. Grolier, N. Mekki et al. 1998. "Low and high responders to pharmacological doses of beta-carotene: Proportion in the population, mechanisms involved and consequences on beta-carotene metabolism." J Lipid Res 39 (11):2250-60.

Borel, P., M. Moussa, E. Reboul et al. 2009. "Human fasting plasma concentrations of vitamin $\mathrm{E}$ and carotenoids, and their association with genetic variants in apo C-III, cholesteryl ester transfer protein, hepatic lipase, intestinal fatty acid binding protein and microsomal triacylglycerol transfer protein." Br J Nutr 101:680-7.

Borel, P., M. Moussa, E. Reboul et al. 2007. "Human plasma levels of vitamin E and carotenoids are associated with genetic polymorphisms in genes involved in lipid metabolism." J Nutr 137 (12):2653-9.

Borel, P., B. Pasquier, M. Armand et al. 2001. "Processing of vitamin A and E in the human gastrointestinal tract.” Am J Physiol Gastrointest Liver Physiol 280 (1):G95-G103.

Bowen, P., V. Garg, M. Stacewiczsapuntzakis, L. Yelton, and R. S. Schreiner. 1993. "Variability of Serum Carotenoids in Reponse to Controlled Diets Containing Six Servings of Fruits and Vegetables per day." Ann. N Y Acad. Sci. 691:241-3. 
Briand, O., V. Touche, S. Colin et al. 2016. "Liver X Receptor Regulates Triglyceride Absorption Through Intestinal Down-regulation of Scavenger Receptor Class B, Type 1." Gastroenterology 150 (3):650-8.

Buttet, M., V. Traynard, T. T. Tran, P. Besnard, H. Poirier, and I. Niot. 2014. "From fatty-acid sensing to chylomicron synthesis: Role of intestinal lipid-binding proteins." Biochimie 96:37-47.

Cheng, H. M., G. Koutsidis, J. K. Lodge, A. Ashor, M. Siervo, and J. Lara. 2017. "Tomato and lycopene supplementation and cardiovascular risk factors: A systematic review and meta-analysis." Atherosclerosis 257:100-108.

Chung, H. Y., A. L. Ferreira, S. Epstein, S. A. Paiva, C. Castaneda-Sceppa, and E. J. Johnson. 2009. "Site-specific concentrations of carotenoids in adipose tissue: Relations with dietary and serum carotenoid concentrations in healthy adults." Am J Clin Nutr 90 (3):533-9.

D'Adamo, C. R., A. D'Urso, K. A. Ryan et al. 2016. "A Common Variant in the SETD7 Gene Predicts Serum Lycopene Concentrations." Nutrients 8 (2):82.

Dallinga-Thie, G. M., R. Franssen, H. L. Mooij et al. 2010. "The metabolism of triglyceriderich lipoproteins revisited: New players, new insight.” Atherosclerosis 211 (1):1-8.

dela Sena, C., S. Narayanasamy, K. M. Riedl, R. W. Curley, Jr., S. J. Schwartz, and E. H. Harrison. 2013. "Substrate specificity of purified recombinant human beta-carotene 15,15'-oxygenase (BCO1)." J Biol Chem 288 (52):37094-103.

Dela Sena, C., J. Sun, S. Narayanasamy et al. 2016. "Substrate specificity of purified recombinant chicken beta-carotene 9',10'-oxygenase (BCO2).” J Biol Chem 291 (28):14609-19.

Desmarchelier, C., and P. Borel. 2017. "Overview of carotenoid bioavailability determinants: From dietary factors to host genetic variations." Trends Food Sci Technol: In press.

Desmarchelier, C., J. C. Martin, R. Planells et al. 2014. "The postprandial chylomicron triacylglycerol response to dietary fat in healthy male adults is significantly explained by a combination of single nucleotide polymorphisms in genes involved in triacylglycerol metabolism." J Clin Endocrinol Metab 99 (3):E484-8.

Diwadkar-Navsariwala, V., J. A. Novotny, D. M. Gustin et al. 2003. "A physiological pharmacokinetic model describing the disposition of lycopene in healthy men." J Lipid Res 44 (10):1927-39.

During, A., H. D. Dawson, and E. H. Harrison. 2005. "Carotenoid transport is decreased and expression of the lipid transporters SR-BI, NPC1L1, and ABCA1 is downregulated in Caco-2 cells treated with ezetimibe." J Nutr 135 (10):2305-12.

Duszka, C., P. Grolier, E. M. Azim, M. C. Alexandre-Gouabau, P. Borel, and V. AzaisBraesco. 1996. "Rat intestinal beta-carotene dioxygenase activity is located primarily in the cytosol of mature jejunal enterocytes." J Nutr 126 (10):2550-6.

Fenni, S., H. Hammou, J. Astier et al. 2017. "Lycopene and tomato powder supplementation similarly inhibit high-fat diet induced obesity, inflammatory response and associated metabolic disorders." Mol Nutr Food Res.

Ferreira, A. L. A., K. J. Yeum, C. Liu et al. 2000. "Tissue distribution of lycopene in ferrets and rats after lycopene supplementation." J Nutr 130 (5):1256-60.

Ferrucci, L., J. R. Perry, A. Matteini et al. 2009. "Common Variation in the beta-Carotene 15,15'-Monooxygenase 1 Gene Affects Circulating Levels of Carotenoids: A GenomeWide Association Study." Am J Hum Genet 84:123-33.

Ford, N. A., A. C. Elsen, and J. W. Erdman, Jr. 2013. "Genetic ablation of carotene oxygenases and consumption of lycopene or tomato powder diets modulate carotenoid and lipid metabolism in mice." Nutr Res 33 (9):733-42.

Forman, M. R., C. B. Borkowf, M. M. Cantwell et al. 2009. "Components of variation in serum carotenoid concentrations: The Polyp Prevention Trial." Eur J Clin Nutr 63 (6):763-70. 
Garcia-Rios, A., P. Perez-Martinez, J. Delgado-Lista, J. Lopez-Miranda, and F. PerezJimenez. 2012. "Nutrigenetics of the lipoprotein metabolism." Mol Nutr Food Res 56 (1):171-83.

Giovannucci, E. 1999. "Tomatoes, tomato-based products, lycopene, and cancer: Review of the epidemiologic literature." J Natl Cancer Inst 91 (4):317-31.

Goulinet, S. and M. J. Chapman. 1997. "Plasma LDL and HDL subspecies are heterogenous in particle content of tocopherols and oxygenated and hydrocarbon carotenoids. Relevance to oxidative resistance and atherogenesis." Arterioscler Thromb Vasc Biol 17 (4):786-96.

Gouranton, E., G. Aydemir, E. Reynaud et al. 2012. "Apo-10'-lycopenoic acid impacts adipose tissue biology via the retinoic acid receptors." Biochim Biophys Acta 1811 (12):1105-14.

Gouranton, E., C. Thabuis, C. Riollet et al. 2011. "Lycopene inhibits proinflammatory cytokine and chemokine expression in adipose tissue." J Nutr Biochem 22:642-8.

Gustin, D. M., K. A. Rodvold, J. A. Sosman et al. 2004. "Single-dose pharmacokinetic study of lycopene delivered in a well-defined food-based lycopene delivery system (tomato paste-oil mixture) in healthy adult male subjects." Cancer Epidemiol Biomarkers Prev $13(5): 850-60$.

Hendrich, S., K. W. Lee, X. Xu, H. J. Wang, and P. A. Murphy. 1994. "Defining food components as new nutrients." J Nutr 124:S1789-S92.

Hu, K. Q., C. Liu, H. Ernst, N. I. Krinsky, R. M. Russell, and X. D. Wang. 2006. “The biochemical characterization of ferret carotene-9',10'-monooxygenase catalyzing cleavage of carotenoids in vitro and in vivo." J Biol Chem 281 (28):19327-38.

Hussain, M. M., S. Fatma, X. Pan, and J. Iqbal. 2005. "Intestinal lipoprotein assembly." Curr Opin Lipidol 16 (3):281-5.

Johnson, E. J., J. Qin, N. I. Krinsky, and R. M. Russell. 1997. "Ingestion by men of a combined dose of beta-carotene and lycopene does not affect the absorption of beta-carotene but improves that of lycopene." J Nutr 127 (9):1833-7.

Kelkel, M., M. Schumacher, M. Dicato, and M. Diederich. 2011. "Antioxidant and antiproliferative properties of lycopene." Free Radic Res 45 (8):925-40.

Korytko, P. J., K. A. Rodvold, J. A. Crowell et al. 2003. "Pharmacokinetics and Tissue Distribution of Orally Administered Lycopene in Male Dogs." J Nutr 133 (9):2788-92.

Leo, M. A., S. Ahmed, S. I. Aleynik, J. H. Siegel, F. Kasmin, and C. S. Lieber. 1995. "Carotenoids and tocopherols in various hepatobiliary conditions." J Hepatol 23 (5):550-6.

Lindqvist, A., and S. Andersson. 2002. "Biochemical properties of purified recombinant human beta-carotene 15,15'-monooxygenase." J Biol Chem 277 (26):23942-8.

Lindshield, B. L., J. L. King, A. Wyss et al. 2008. "Lycopene biodistribution is altered in 15,15'-carotenoid monooxygenase knockout mice.” J Nutr 138 (12):2367-71.

Lobo, G. P., J. Amengual, D. Baus, R. A. Shivdasani, D. Taylor, and J. von Lintig. 2013. "Genetics and diet regulate vitamin A production via the homeobox transcription factor ISX.” J Biol Chem 288:9017-27.

Lobo, G. P., J. Amengual, G. Palczewski, D. Babino, and J. von Lintig. 2012. "Mammalian carotenoid-oxygenases: Key players for carotenoid function and homeostasis." Biochim Biophys Acta 1821 (1):78-87.

Lobo, G. P., S. Hessel, A. Eichinger et al. 2010. "ISX is a retinoic acid-sensitive gatekeeper that controls intestinal beta,beta-carotene absorption and vitamin A production." Faseb $J 24$ (6):1656-66.

Marcotorchino, J., B. Romier, E. Gouranton et al. 2012. "Lycopene attenuates LPS-induced TNF-alpha secretion in macrophages and inflammatory markers in adipocytes exposed to macrophage-conditioned media." Mol Nutr Food Res 56 (5):725-32. 
Mathews-Roth, M. M., S. Welankiwar, P. K. Sehgal, N. C. Lausen, M. Russett, and N. I. Krinsky. 1990. "Distribution of [14C]canthaxanthin and [14C]lycopene in rats and monkeys." J Nutr 120 (10):1205-13.

Mein, J. R., F. Lian, and X. D. Wang. 2008. "Biological activity of lycopene metabolites: Implications for cancer prevention." Nutr Rev 66 (12):667-83.

Moran, N. E., J. W. Erdman, Jr., and S. K. Clinton. 2013. "Complex interactions between dietary and genetic factors impact lycopene metabolism and distribution." Arch Biochem Biophys 539 (2):171-80.

Mordente, A., B. Guantario, E. Meucci et al. 2011. "Lycopene and cardiovascular diseases: An update." Curr Med Chem 18 (8):1146-63.

Moussa, M., E. Gouranton, B. Gleize et al. 2011. "CD36 is involved in lycopene and lutein uptake by adipocytes and adipose tissue cultures." Mol Nutr Food Res 55:578-84.

Moussa, M., J. F. Landrier, E. Reboul et al. 2008. "Lycopene absorption in human intestinal cells and in mice involves scavenger receptor class B type I but not Niemann-Pick C1-like 1." J Nutr 138 (8):1432-6.

O'Neill, M. E. and D. I. Thurnham. 1998. "Intestinal absorption of b-carotene, lycopene and lutein in men and women following a standard meal: Response curves in the triacylglycerol-rich lipoprotein fraction." Br J Nutr 79:149-59.

Perez-Martinez, P., J. Delgado-Lista, F. Perez-Jimenez, and J. Lopez-Miranda. 2010. “Update on genetics of postprandial lipemia." Atheroscler Suppl 11 (1):39-43.

Reboul, E., A. Berton, M. Moussa, C. Kreuzer, I. Crenon, and P. Borel. 2006. "Pancreatic lipase and pancreatic lipase-related protein 2, but not pancreatic lipase-related protein 1, hydrolyze retinyl palmitate in physiological conditions." Biochim Biophys Acta 1761 (1):4-10.

Reboul, E. and P. Borel. 2011. "Proteins involved in uptake, intracellular transport and basolateral secretion of fat-soluble vitamins and carotenoids by mammalian enterocytes." Prog Lipid Res 50:388-402.

Richelle, M., P. Lambelet, A. Rytz et al. 2012. "The proportion of lycopene isomers in human plasma is modulated by lycopene isomer profile in the meal but not by lycopene preparation." Br J Nutr 107:1482-8.

Richelle, M., B. Sanchez, I. Tavazzi, P. Lambelet, K. Bortlik, and G. Williamson. 2010. "Lycopene isomerisation takes place within enterocytes during absorption in human subjects." Br J Nutr 103 (12):1800-7.

Romanchik, J. E., D. W. Morel, and E. H. Harrison. 1995. "Distributions of carotenoids and alpha-tocopherol among lipoproteins do not change when human plasma is incubated in vitro." J Nutr 125:2610-17.

Ross, A. B., T. Vuong le, J. Ruckle et al. 2011. "Lycopene bioavailability and metabolism in humans: An accelerator mass spectrometry study." Am J Clin Nutr 93 (6):1263-73.

Schmitz, H. H., C. L. Poor, R. B. Wellman, and J. W. J. Erdman. 1991. "Concentrations of selected carotenoids and vitamin A in human liver, kidney and lung tissue." J Nutr 121:1613-21.

Shmarakov, I., M. K. Fleshman, D. N. D’Ambrosio et al. 2010. "Hepatic stellate cells are an important cellular site for beta-carotene conversion to retinoid." Arch Biochem Biophys 504 (1):3-10.

Stahl, W., W. Schwarz, A. R. Sundquist, and H. Sies. 1992. "Cis-trans isomers of lycopene and beta-carotene in human serum and tissues." Arch Biochem Biophys 294 (1):173-7.

Stahl, W. and H. Sies. 1992. "Uptake of lycopene and its geometrical isomers is greater from heat-processed than from unprocessed tomato juice in humans." J Nutr 121:2161-6.

Story, E. N., R. E. Kopec, S. J. Schwartz, and G. K. Harris. 2010. "An update on the health effects of tomato lycopene." Annu Rev Food Sci Technol 1:189-210. 
Teodoro, A. J., D. Perrone, R. B. Martucci, and R. Borojevic. 2009. "Lycopene isomerisation and storage in an in vitro model of murine hepatic stellate cells." Eur J Nutr 48 (5):261-8.

Tyssandier, V., G. Choubert, P. Grolier, and P. Borel. 2002. "Carotenoids, mostly the xanthophylls, exchange between plasma lipoproteins." Int J Vitam Nutr Res 72 (5):300-308.

Tyssandier, V., B. Lyan, and P. Borel. 2001. "Main factors governing the transfer of carotenoids from emulsion lipid droplets to micelles.” Biochim Biophys Acta 1533 (3):285-92.

Tyssandier, V., E. Reboul, J. F. Dumas et al. 2003. "Processing of vegetable-born carotenoids in the human stomach and duodenum." Am J Physiol Gastrointest Liver Physiol 284 (6):G913-23.

van der Sijde, M. R., A. Ng, and J. Fu. 2014. "Systems genetics: From GWAS to disease pathways.” Biochim Biophys Acta 1842 (10):1903-9.

Viuda-Martos, M., E. Sanchez-Zapata, E. Sayas-Barbera, E. Sendra, J. A. Perez-Alvarez, and J. Fernandez-Lopez. 2014. "Tomato and tomato byproducts. Human health benefits of lycopene and its application to meat products: A review." Crit Rev Food Sci Nutr 54 (8):1032-49.

Wang, T. T., A. J. Edwards, and B. A. Clevidence. 2013. "Strong and weak plasma response to dietary carotenoids identified by cluster analysis and linked to betacarotene 15,15'-monooxygenase 1 single nucleotide polymorphisms." J Nutr Biochem 24:1538-46.

Wei, W., Y. Kim, and N. Boudreau. 2001. "Association of smoking with serum and dietary levels of antioxidants in adults: NHANES III, 1988-1994.” American Journal of Public Health 91 (2):258-64.

Zaripheh, S., T. W. Boileau, M. A. Lila, and J. W. Erdman, Jr. 2003. "[14C]-lycopene and [14C]-labeled polar products are differentially distributed in tissues of F344 rats prefed lycopene." J Nutr 133 (12):4189-95.

Zaripheh, S. and J. W. Erdman, Jr. 2005. "The biodistribution of a single oral dose of [14C]-lycopene in rats prefed either a control or lycopene-enriched diet." J Nutr 135 (9):2212-18.

Zou, J. and D. Feng. 2015. "Lycopene reduces cholesterol absorption through the downregulation of Niemann-Pick C1-like 1 in Caco-2 cells." Mol Nutr Food Res 59 (11):2225-30.

Zubair, N., C. Kooperberg, J. Liu, C. Di, U. Peters, and M. L. Neuhouser. 2015. "Genetic variation predicts serum lycopene concentrations in a multiethnic population of postmenopausal women." J Nutr 145 (2):187-92.

Neccesary to include this?
Author Contributions: P. Borel, C. Desmarchelier and J.F. Landrier have equally contributed to the writing of this review.

Conflicts of Interest: The authors declare no conflict of interest. 
